\title{
Difficult to control atopic dermatitis
}

\author{
Ulf Darsow ${ }^{1,2^{*}}$, Andreas Wollenberg ${ }^{3}$, Dagmar Simon ${ }^{4}$, Alain Taïeb ${ }^{5}$, Thomas Werfel ${ }^{6}$, Arnold Oranje ${ }^{7}$, \\ Carlo Gelmetti ${ }^{8}$, Ake Svensson ${ }^{9}$, Mette Deleuran ${ }^{10}$, Anne-Marie Calza ${ }^{11}$, Francesca Giusti ${ }^{12}$, Jann Lübbe ${ }^{11}$, \\ Stefania Seidenari ${ }^{12}$, Johannes Ring ${ }^{1,2}$ For the European Task Force on Atopic Dermatitis / EADV Eczema Task \\ Force
}

\begin{abstract}
Difficult to control atopic dermatitis (AD) presents a therapeutic challenge and often requires combinations of topical and systemic treatment. Anti-inflammatory treatment of severe AD most commonly includes topical glucocorticosteroids and topical calcineurin antagonists used for exacerbation management and more recently for proactive therapy in selected cases. Topical corticosteroids remain the mainstay of therapy, the topical calcineurin inhibitors tacrolimus and pimecrolimus are preferred in certain locations. Systemic anti-inflammatory treatment is an option for severe refractory cases. Microbial colonization and superinfection contribute to disease exacerbation and thus justify additional antimicrobial / antiseptic treatment. Systemic antihistamines ( $\mathrm{H} 1)$ may relieve pruritus but do not have sufficient effect on eczema. Adjuvant therapy includes UV irradiation preferably of UVA1 wavelength. "Eczema school" educational programs have been proven to be helpful.
\end{abstract}

Keywords: Atopic dermatitis, Eczema, Therapy, Guideline

\section{Introduction}

Atopic dermatitis (AD, atopic eczema, eczema) is an inflammatory, chronically relapsing, and intensely pruritic skin disease occurring often in families with atopic diseases (atopic dermatitis, bronchial asthma and/or allergic rhino-conjunctivitis) [1]. Less than $10 \%$ are regarded as severe cases because of disease intensity and extent (SCORAD > 40) or refractory to treatment. Reasons for severe courses of $\mathrm{AD}$ are based on individual (e.g. genetic, barrier function, allergies) risc factors and sometimes on therapeutic problems like misunderstandings with regard to topical treatment. Management of exacerbated AD is a therapeutic challenge, as it requires efficient short-term control of acute symptoms, without compromising the overall management plan that is aimed at long-term stabilization, flare prevention, and avoidance of side effects.

Exacerbations may sometimes uncover relevant provocation factors, for example contact allergy, or infection. This synopsis on refractory $\mathrm{AD}$ excludes the general principles of $\mathrm{AD}$ treatment like basic skin care and management of

\footnotetext{
* Correspondence: ulf.darsow@|rz.tum.de

'Department of Dermatology and Allergy Biederstein, Technische Universität München, Munich, Germany

${ }^{2}$ ZAUM - Center for Allergy and Environment, Munich, Germany

Full list of author information is available at the end of the article
}

food allergy, as these main strategies are published elsewhere in guidelines [2]. Nevertheless, these basic rules have to be included in the management of all severe cases, too. Figure 1 summarizes the general treatment options.

\section{Contact allergy}

The role of contact allergy in AD patients is frequently underestimated $[3,4]$. The frequency of contact sensitization in $\mathrm{AD}$, ranging from $41 \%$ to $64 \%$ according to recent observations, supports the importance of systematic patch testing in atopic patients, adults and children. The most common contact sensitizers are metals, fragrance, preservatives, dyes, neomycin, and lanolin, but contact allergy to topical glucocorticosteroids is also not rare in $\mathrm{AD}$ patients.

Contact sensitization may worsen the skin condition of AD patients and influence the course of the disease. Moreover, sensitized AD subjects may respond to very low concentrations of contact allergens, because of their impaired skin barrier function and hyper-reactivity to irritant stimuli enhancing contact reactions.

\section{Ciomed Central}

(c) 2013 Darsow et al.; licensee BioMed Central Ltd. This is an Open Access article distributed under the terms of the Creative Commons Attribution License (http://creativecommons.org/licenses/by/2.0), which permits unrestricted use, distribution, and reproduction in any medium, provided the original work is properly cited. 


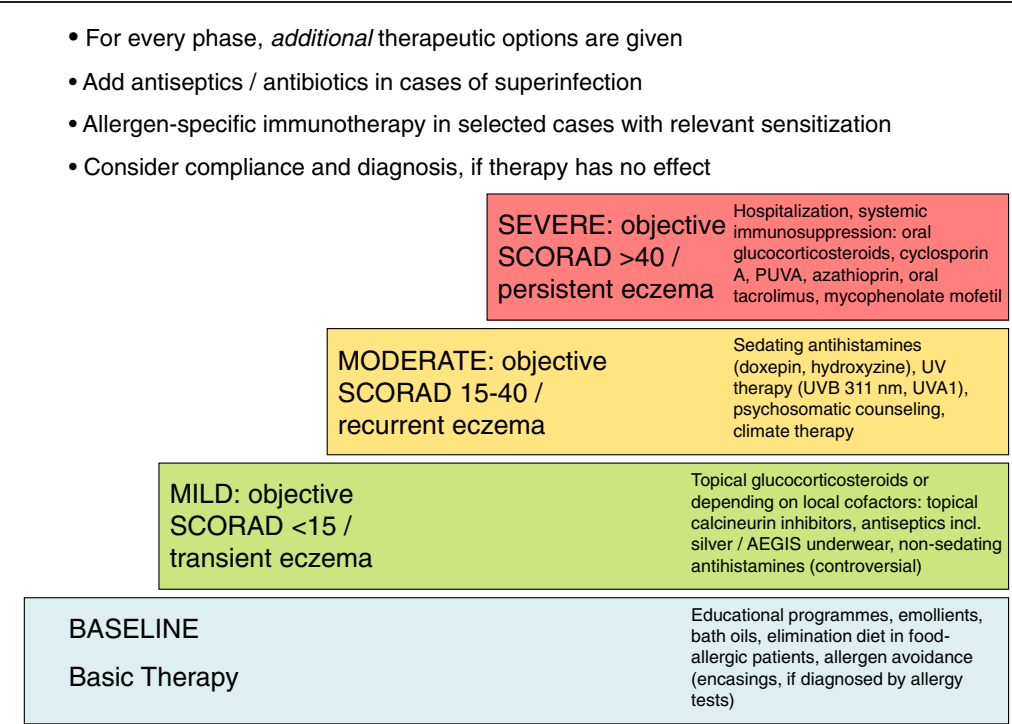

Figure 1 Recommendation for treatment of adult eczema / atopic dermatitis according to graded severity (modified from 44).

Topical anti-inflammatory treatment

\section{Topical treatment}

The use of wet-wrap dressings with (diluted) corticosteroids for up to 14 days (usually applied for 3 days) is a safe crisis intervention treatment of severe and/or refractory $\mathrm{AD}$ with temporary systemic bioactivity of the corticosteroids as the only reported serious side-effects $[5,6]$. By tradition, antiinflammatory topical therapy has been administered to lesional skin only and has been stopped or tapered down once visible lesions were cleared. This traditional, reactive approach has in the last years been challenged by the proactive treatment concept, which is defined as a combination of pre-defined, long-term, low dose, anti-inflammatory treatment applied to previously affected areas of skin in combination with liberal use of emollients on the entire body and a predefined appointment schedule for clinical control examinations $[7,8]$.

\section{Corticosteroids}

Topical corticosteroids (TCS) are a first line antiinflammatory treatment, applied on inflammatory skin lesions according to needs (pruritus, sleeplessness, new flare). Proactive therapy for flare prevention is also possible with TCS.Topical corticosteroids are grouped by potency, which should be known to prescribers. Potent and very potent corticosteroids (group III and IV) are more likely to cause depression of adrenal function than group I (mild) and II (moderate strength) treatments, but their systemic effects will decrease more quickly due to more rapid restitution of the skin barrier $[9,10]$. However, potency ranking of topical steroids in some countries including the US is the reverse of the European system with class I (superpotent) to class VII (low potency). For severe AD, group II and group III (EU system) glucocorticosteroids are recommended. Itch is the key symptom for evaluation of response to treatment, and tapering should not be initiated before the itch has disappeared. Dose tapering should be gradual in order to avoid withdrawal rebound. Tapering strategies consist in using a less potent corticosteroid on a daily base, or keeping a more potent one while reducing the frequency of application (intermittent regimen).

\section{Topical calcineurin inhibitors}

Both topical calcineurin inhibitors (TCI), tacrolimus ointment $(0.1 \%$ and $0.03 \%)$ and pimecrolimus cream (1\%), are licensed for topical eczema treatment. Various aspects of these drugs have been reviewed in detail [11]. The efficacy of both formulations has been demonstrated against placebo in clinical trials for short term [12,13] and long term use of these substances [14,15]. In addition, proactive tacrolimus ointment therapy has been shown to be safe and effective for up to one year in reducing the number of flares and improving the quality of life in adult patients and children [16,17]. The anti-inflammatory potency of $0.1 \%$ tacrolimus ointment is similar to a corticosteroid with intermediate activity [18], while the latter is clearly more active than $1.0 \%$ pimecrolimus cream [19].

\section{Antihistamines}

Systemic antihistamines (anti H1) are widely used in acute flares against itch, however few controlled studies are available [20]. Antihistamines may be helpful in decreasing pruritus and permit sleep during flares. In 
this setting, sedative anti $\mathrm{H} 1$ molecules such as hydroxyzine are recommended by clinicians as helpful. Concerning the newer non-sedating H1R specific antihistamines, controlled studies did not show significant effects on eczema.

\section{Anti-bacterial and antimycotic therapy}

A number of defects in innate and adaptive immunity may explain the high rate of cutaneous colonization with Staphylococcus aureus (up to $90 \%$ in moderate to severe eczema) in $\mathrm{AD}$ [21]. There is evidence that a decrease in microbiome diversity is associated with an increased colonization with $S$. aureus as well as increase in disease activity. Antibiotic eradication of $S$. aureus may therefore not always be an appropriate long-term strategy, especially with regard to the increasing prevalence of antibiotic resistance [22-24]. In particular topical antibiotics should not be used for longer periods in the treatment of AD. There is evidence for an association of $S$. aureus-derived superantigens with disease exacerbation [25,26], supporting early observations that the density of $S$. aureus colonization in AD is significantly correlated with clinical severity [27], and that patients with severe $\mathrm{AD}$ may improve (but not be cured) by anti-staphylococcal treatment [28]. In general, improvement of eczema by anti-inflammatory therapy (i.e. TCS, TCI, UV) decreases S. aureus colonization.

Other secondary infections, such as yeasts, dermatophytes, and streptococcal infections have also been implicated as disease factors in $\mathrm{AD}$ (for a review, see [22]). Intense, fleshy erythema in skin folds of children with a flare of AD may warrant a search for streptococcal skin infection. In general, signs of secondary infections should be treated if present. Ketoconazole and ciclopiroxolamine are proposed for topical treatment of "head and neck" AD, often associated with Malassezia sympodialis superinfection [29,30].

\section{Phototherapy}

Except UVA1, which was shown to be effective in managing $\mathrm{AD}$ flares, phototherapy is not indicated in the acute stages of $\mathrm{AD}$, but apt to treat chronic, pruritic, lichenified forms. However, it should not be prescribed in patients who experienced a worsening of their dermatosis during sun exposure. Usually, phototherapy is part of a total treatment plan in addition to topical anti-inflammatory and antimicrobial therapy. As second-level treatment it is used especially in adults. Phototherapy in children younger than 12 years should not be applied under normal circumstances.

Present UV sources include equipments able to emit selective spectra of radiations

- Broadband UV (UVA+UVB = 290-400 nm)

- Narrow-band UVB (nbUVB = peak:311-313 nm)

- UVA1 (340-400 nm).
nbUVB has been indicated for chronic-moderate forms of $\mathrm{AD}$ [31] and is currently preferred to broadband UV because it is less erythemogenic, while high dose UVA1 has been prescribed for more severe phases [31].

\section{Systemic anti-inflammatory therapy}

Non-response to adequately applied topical therapy is rare, and systemic anti-inflammatory treatment should be limited to severe cases in which the potential of topical treatment (or of patient compliance) has been exhausted. An actual overview of the different options has been published [32]. Corticosteroids are rapidly effective, but should only be used for a few weeks, for severe acute exacerbations, because of the many long term side-effects. In severe chronic cases consider starting another systemic anti-inflammatory therapy while tapering the corticosteroid.

The usefulness of both cyclosporin (3-5 mg/kg/day) and azathioprine $(2.5 \mathrm{mg} / \mathrm{kg} /$ day $)$ has been well documented in clinical trials with children and adults [33-36]. Cyclosporin A therapy is rapidly effective, but has a narrow therapeutic index and requires a close follow-up of renal function. It is an approved substance for systemic treatment of $\mathrm{AD}$ in many countries and is frequently used for systemic immunosuppressive therapy in AD.

Azathioprine has a slower onset of action and is not always well tolerated. Low TPMT (thiopurinemethyltransferase) activity is associated with an increased myelotoxicity of azathioprine, but patients at risk can be identified by pre-treatment screening for TMTP activity [35].

Mycophenolate mofetil (2g/day) seems to offer a comparatively more favourable safety profile and its usefulness in severe $\mathrm{AD}$ is documented in both prospective and retrospective studies [37-39], but remains to be assessed in larger randomized trials.

Methotrexate is used by many clinicians as an alternative treatment. Only a few studies have documented its effect and more randomised trials are needed [40].

Biologic agents (biologicals) present new therapeutic tools in the treatment of recalcitrant AD. They specifically target inflammatory cells and mediators, respectively, and thus may inhibit pathogenically relevant pathways. A number of case reports and pilot studies have been published recently, however representative, randomized, placebo controlled studies evaluating the efficacy and safety of biologicals in AD are still not available. Approaches resulting in reduced $\mathrm{T}$ cell activation using agents such as alefacept (fusion protein of lymphocyte function antigen (LFA)-3 (CD58) and immunoglobulin (Ig)G, rituximab (anti-CD20 antibody) and efalizumab (anti-CD11a antibody, no longer available) have been shown to be effective in selected patients with moderate to severe $\mathrm{AD}$ and were mentioned in guidelines [2,41-44]. 


\section{Educational programs and counselling}

In the last decade, education programs for patients and parents were established in different countries in Europe, but also in North and South America (see www.opened-dermatology.com). Standardized interdisciplinary programs involving dermatologists, paediatricians, psychologists / psychosomatic counsellors, and dietary counselling have been demonstrated to support the improvement of subjective and objective symptoms, and optimize medication use in patients, and result in a significant gain in quality of life [45]. Participation in one of these programs is highly encouraged.

\section{Competing interests}

U. Darsow has been speaker, investigator and / or been a member of advisory boards for Allergopharma, ALK-Abello, Bencard, GSK, Hermal, Novartis, Stallergenes, Stiefel. M. Deleuran is speaker, investigator and/or advisor for Leo Pharma, Pierre Fabre, MEDA and Astellas. J. Ring conducted clinical trials or research for ALK-Abello, Allergopharma, Allmirall-Hermal, Astellas, Bencard, Biogen-Idec, Galderma, GSK, Leo, MSD, Novartis, Phadia, PLS Design, Stallergenes. A. Wollenberg has received research funding and lecture honoraria from, conducted clinical trials for, or is a paid consultant to Astellas, Basilea, Galderma, GSK, Loreal, MEDA, Merck, Novartis, Pierre Fabre, MSD. Other authors declared that they have no competing interests.

\section{Authors' contributions}

UD coordinated and participated in the consensus process and drafted the manuscript. AW, DS, AT, TW, AO, CG, AS, MD, AMC, FG, JL, SS and JR participated in the consensus process and drafted the manuscript. All authors read and approved the final manuscript.

\section{Authors' information}

European Task Force on Atopic Dermatitis / EADV Eczema Task Force: O. Baadsgaard, Hellerup, Denmark; T. Bieber, Bonn, Germany; E. Bonifazi, Bari, Italy; C.A.F.M. Bruijnzeel-Koomen, Utrecht, The Netherlands; A. M. Calza, Geneva, Switzerland; M. Deleuran, Aarhus,Denmark; U. Darsow, Munich, Germany; J. De la Cuadra, Valencia, Spain; L. De Raeve, Brussels, Belgium; T.L. Diepgen, Heidelberg, Germany; P. Dupuy, Castanet Tolosan, France; G. Fabrizi, Rome, Italy; C. Gelmetti, Milan, Italy; A. Giannetti, Modena, Italy; U. Gieler, Gießen, Germany; F. Giusti, Modena, Italy; J. Harper, London, England; E.A Holm, Copenhagen, Denmark; M. Kägi, Zürich, Switzerland; O. Kekki, Tampere, Finland; B. Kunz, Hamburg, Germany; R. Lever, Glasgow, Scotland; J. Lübbe, Geneva, Switzerland; A.B. Olesen, Aarhus, Denmark; A. P. Oranje, Rotterdam, The Netherlands; Y. de Prost, Paris, France; G. Rajka, Oslo, Norway; T. Reunala, Tampere, Finland; J. Revuz, Créteil, France; J. Ring, Munich, Germany; S. Seidenari, Modena, Italy; D. Simon, Bern, Switzerland; M. Song, Brussels, Belgium; J.F. Stalder, Nantes, France; A. Svensson, Malmö, Sweden; A. Taïeb, Bordeaux, France; D. Tennstedt, Brussels, Belgium; K. Turjanmaa, Tampere, Finland; C. Vestergaard, Aarhus, Denmark; T. Werfel, Hannover, Germany; A. Wollenberg, Munich, Germany

\section{Author details}

${ }^{1}$ Department of Dermatology and Allergy Biederstein, Technische Universität München, Munich, Germany. ${ }^{2}$ ZAUM - Center for Allergy and Environment, Munich, Germany. ${ }^{3}$ Department of Dermatology and Allergy, Ludwig-Maximilians-University Munich, Munich, Germany. ${ }^{4}$ Department of Dermatology, Inselspital, Bern University Hospital, University of Bern, Bern, Switzerland. ${ }^{5}$ Service de Dermatologie, Hopital St André, Bordeaux, France. ${ }^{6}$ Hautklinik Linden, Deptartment of Dermatology MHH, Hannover, Germany. ${ }^{7}$ Department of Pediatrics (Pediatric Dermatology Unit), ERASMUS MC, Rotterdam, The Netherlands. ${ }^{8}$ Department of Pathophysiology and Transplantation, University of Milan, Ospedale Maggiore Policlinico, Milan, Italy. ${ }^{9}$ Department of Dermatology, University Hospital UMAS, Malmö, Sweden. ${ }^{10}$ Department of Dermatology, Aarhus University Hospital, Aarhus, Denmark. ${ }^{11}$ Clinique de Dermatologie, Hôpital Cantonal Universitaire, Genève, Suisse, Switzerland. ${ }^{12}$ Department of Dermatology, University of Modena and Reggio Emilia, Modena, Italy.
Received: 20 November 2012 Accepted: 4 March 2013

Published: 14 March 2013

\section{References}

1. Ring J, Przybilla B, Ruzicka T (Eds): Handbook of atopic eczema. 2nd edition. Heidelberg: Springer; 2006.

2. Ring J, Alomar A, Bieber T, Deleuran M, Fink-Wagner A, Gelmetti C, Gieler G, Lipozencic J, Luger T, Oranje AP, Schäfer T, Schwennesen T, Seidenari S, Simon D, Ständer S, Stingl G, Szalai S, Szepietowski JC, Taïeb A, Werfel T, Wollenberg A, Darsow U: Guidelines for Treatment of Atopic Eczema (Atopic Dermatitis) Part I. J Eur Acad Dermatol Venereol 2012, 26:1045-1060

3. Manzini BM, Ferdani G, Simonetti V, Donini M, Seidenari S: Contact sensitization in children. Contact Dermatitis 1998, 15:12-17.

4. Mortz CG, Andersen KE: Allergic contact dermatitis in children and adolescents. Contact Dermatitis 1999, 41:121-130.

5. Devillers AC, Oranje AP: Efficacy and safety of 'wet-wrap' dressings as an intervention treatment in children with severe and/or refractory atopic dermatitis: a critical review of the literature. Br J Dermatol 2006, 154:579-585.

6. Schnopp C, Holtmann C, Stock S, Remling R, Fölster-Holst R, Ring J, Abeck $D$ : Topical steroids under wet-wrap dressings in atopic dermatitis-a vehicle-controlled trial. Dermatology 2002, 204:56-59.

7. Wollenberg A, Bieber T: Proactive therapy of atopic dermatitis -an emerging concept. Allergy 2009, 64:276-278.

8. Van der Meer JB, Glazenburg EJ, Mulder PG, Eggink HF, Coenraads PJ: The management of moderate to severe atopic dermatitis in adults with topical fluticasone propionate. The Netherlands Adult Atopic Dermatitis Study Group. Br J Dermatol 1999, 140:1114-1121.

9. Feiwel M, Munro D, James V: Effect of topically applied $0.1 \%$ betamethasone valerate ointment on the adrenal function of children. In Thirteenth congress of International Dermatology. Berlin: Springer; 1968:202-204

10. Walsh P, Aeling J, Huff L, Weston W: Hypothalamus-pituitary-adrenal axis suppression by superpotent topical steroids. J Am Acad Dermatol 1993, 29:501-503.

11. Bornhövd E, Burgdorf WHC, Wollenberg A: Macrolactam immunomodulators for topical treatment of inflammatory skin diseases. J Am Acad Dermatol 2001, 45:736-743.

12. Ruzicka T, Bieber T, Schöpf E, Rubins A, Dobozy A, Bos J, et al: A short-term trial of tacrolimus ointment for atopic dermatitis. N Engl J Med 1997 337:816-821.

13. Van Leent EJ, Graber M, Thurston M, Wagenaar A, Spuls PI, Bos JD: Effectiveness of the ascomycin macrolactam SDZ ASM 981 in the topical treatment of atopic dermatitis. Arch Dermatol 1998, 134:805-809.

14. Reitamo S, Wollenberg A, Schöpf E, Perrot JL, Marks R, Ruzicka T, et al: Safety and efficacy of 1 year of tacrolimus ointment monotherapy in adults with atopic dermatitis. Arch Dermatol 2000, 136:999-1006.

15. Meurer M, Fölster-Holst R, Wozel G, Weidinger G, Jünger M, Bräutigam M: Pimecrolimus cream in the long-term management of atopic dermatitis in adults: a six-month study. Dermatology 2002, 205:271-277.

16. Wollenberg A, Reitamo S, Girolomoni G, Lahfa M, Ruzicka T, Healy E, Giannetti A, Bieber T, Vyas J, Deleuran M: Proactive treatment of atopic dermatitis in adults with $0.1 \%$ tacrolimus ointment. Allergy 2008 , 63:742-750.

17. Thaci D, Reitamo S, Gonzalez Ensenat MA, Moss C, Boccaletti V, Cainelli T, Van Der Valk P, Buckova H, Sebastian M, Schuttelaar M, Ruzicka T: Proactive disease management with $0.03 \%$ tacrolimus ointment for children with atopic dermatitis: results of a randomized, multicentre, comparative study. Br J Dermatol 2008, 159:1348-1356.

18. Reitamo S, Rustin M, Ruzicka T, Cambazard F, Kalimo K, Friedmann P, et al: Efficacy and safety of tacrolimus ointment compared with hydrocortisone butyrate ointment in adult patients with atopic dermatitis. J Allergy Clin Immunol 2002, 109:547-555.

19. Luger T, Van Leent $E$, Graeber M, Hedgecock S, Thurston M, Kandra A, et al: SDZ ASM 981: an emerging safe and effective treatment for atopic dermatitis. Br J Dermatol 2001, 144:788-794.

20. Diepgen TL: Long-term treatment with cetirizine of infants with atopic dermatitis: a multi-country, double-blind, randomized, placebocontrolled trial (the ETAC trial) over 18 months. Pediatr Allergy Immunol 2002, 13:278-286. 
21. De Benedetto A, Agnihothri R, McGirt LY, Bankova LG, Beck LA: Atopic dermatitis: a disease caused by innate immune defects. $J$ Invest Dermatol 2009, 129:14-30-22.

22. Lübbe J: Secondary infections in patients with atopic dermatitis. Am J Clin Dermatol 2003, 4:641-654.

23. Shah M, Mohanraj M: High levels of fusidic acid resistant Staphylococcus aureus in dermatology patients. Br J Dermato/ 2003, 148:1018-1020.

24. Niebuhr M, Mai U, Kapp A, Werfel T: Antibiotic treatment of cutaneous infections with Staphylococcus aureus in patients with atopic dermatitis: current antimicrobial resistances and susceptibilities. Exp Dermatol 2008, 17:953-957.

25. Bunikowski R, Mielke M, Skarabis H, Worm M, Anagnostopoulos I, Kolde G, et al: Evidence for a disease-promoting effect of staphylococcus aureus-derived exotoxins in atopic dermatitis. J Allergy Clin Immunol 2000, 105:814-819.

26. Zollner T, Wichelhaus T, Hartung A, Von Mallinckrodt C, Wagner T, Brade V, et al: Colonization with superantigen-producing staphylococcus aureus is associated with increased severity of atopic dermatitis. Clin Exp Allergy 2000, 30:994-1000

27. Hauser C, Wuethrich B, Matter L: Staphylococcus aureus skin colonization in atopic dermatitis. Dermatologica Helvetica 1985, 170:35.

28. Breuer K, Haussler S, Kapp A, Werfel T: Staphylococcus aureus: colonizing features and influence of an antibacterial treatment in adults with atopic dermatitis. Br J Dermatol 2002, 147:55-61.

29. Lintu P, Savolainen J, Kortekangas-Savolainen O, Kalimo K: Systemic ketoconazole is an effective treatment of atopic dermatitis with lgEmediated hypersensitivity to yeasts. Allergy 2001, 56:512-517.

30. Mayser P, Kupfer J, Nemetz D, Schäfer U, Nilles M, Hort W, Gieler U: Treatment of head and neck dermatitis with ciclopiroxolamine cream results of a double-blind, placebo-controlled study. Skin Pharmacol Physiol 2006, 19:153-158.

31. Williams HC, Grindlay DJ: What's new in atopic eczema? An analysis of the clinical significance of systematic reviews on atopic eczema published in 2006 and 2007. Clin Exp Dermatol 2008, 33:685-688.

32. Akhavan A, Rudikoff D: Atopic dermatitis: systematic immunosuppressive therapy. Semin Cutan Med Surg 2008, 27:151-155.

33. Berth-Jones L, Finlay A, Zaki I, Tan B, Goodyear H, Lewis-Jones S, et al: Ciclosporin in severe childhood atopic dermatitis: a multicentre study. J Am Acad Dermatol 1996, 34:1016-1021.

34. Van Joost $T$, Heule F, Korstanje M, Van-den-Broek M, Stenveld $H$, Van-Vloten W: Ciclosporin in atopic dermatitis: a multicentre, placebo-controlled study. Br J Dermatol 1994, 130:634-640.

35. Murphy LA, Atherton D: A retrospective evaluation of azathioprine in severe childhood atopic eczema, using thiopurine methyltransferase levels to exclude patients at high risk of myelosuppression. $\mathrm{Br} J$ Dermatol 2002, 147:308-315.

36. Berth-Jones J, Takwale A, Tan E, Barclay G, Agarwal S, Ahmed I, et al: Azathioprine in severe adult atopic dermatitis: a double-blind, placebocontrolled, crossover trial. Br J Dermatol 2002, 147:324-330.

37. Grundmann-Kollmann M, Podda M, Ochsendorf F, Boehncke W-H, Kaufmann R, Zollner T: Mycophenolate mofetil is effective in the treatment of atopic dermatitis. Arch Dermatol 2001, 137:870-873.

38. Heller M, Shin HT, Orlow SJ, Schaffer JV: Mycophenolate mofetil for severe childhood atopic dermatitis: experience in 14 patients. $\mathrm{Br} J$ Dermatol 2007, 157:127-132

39. Murray ML, Cohen JB: Mycophenolate mofetil therapy for moderate to severe atopic dermatitis. Clin Exp Dermatol 2007, 32:23-27.

40. Goujon C, Berard F, Dahel K, Guillot I, Hennino A, Nosbaum A, Saad N, Nicolas JF: Methotrexate for the treatment of adult atopic dermatitis. Eur J Dermatol 2006, 16:155-158.

41. Simon D, Wittwer J, Kostylina G, Buettiker U, Simon HU, Yawalkar N: Alefacept (lymphocyte function-associated molecule 3/lgG fusion protein) treatment for atopic eczema. J Allergy Clin Immunol 2008, 122:423-424.

42. Moul DK, Routhouska SB, Robinson MR, Korman NJ: Alefacept for moderate to severe atopic dermatitis: a pilot study in adults. J Am Acad Dermatol 2008, 58:984-989.

43. Simon D, Hösli S, Kostylina G, Yawalkar N, Simon HU: Anti-CD20 (rituximab) treatment improves atopic eczema. J Allergy Clin Immunol 2008, 121:122-128.
44. Darsow U, Wollenberg A, Simon D, Taïeb A, Werfel T, Oranje A, Gelmetti C, Svensson A, Deleuran M, Calza AM, Giusti F, Lübbe J, Seidenari S, Ring J for the European Task Force on Atopic Dermatitis / EADV Eczema Task Force: ETFAD / EADV Eczema Task Force 2009 position paper on diagnosis and treatment of atopic dermatitis. J Eur Acad Dermatol Venereol 2010, 24:317-328.

45. Staab D, Diepgen TL, Fartasch M, Kupfer J, Lob-Corzilius T, Ring J, et al: Age related, structured educational programmes for the management of atopic dermatitis in children and adolescents: multicentre, randomised controlled trial. BMJ 2006, 332:933-938.

doi:10.1186/1939-4551-6-6

Cite this article as: Darsow et al:: Difficult to control atopic dermatitis. World Allergy Organization Journal 2013 6:6.

\section{Submit your next manuscript to BioMed Central and take full advantage of:}

- Convenient online submission

- Thorough peer review

- No space constraints or color figure charges

- Immediate publication on acceptance

- Inclusion in PubMed, CAS, Scopus and Google Scholar

- Research which is freely available for redistribution 